\title{
The effect of amygdalectomy on acquisition of a classically conditioned fear response*
}

\author{
MELVIN L. GOLDSTEIN \\ Indiana University at Kokomo, Kokomo, Indiana 46901
}

\begin{abstract}
Rats were subjected to bilateral amygdalectomy and their performance latencies on acquisition of the classically conditioned fear response were compared with the performance of normal animals. Bilateral amygdalectomy was found to interfere with acquisition of a classically conditioned fear response. Amygdalectomy also reduced the general level of activity. The amygdaloid complex is, therefore, essential for the acquisition of fear motivated behaviors. This finding is consistent with the results obtained for other fear motivated behavior such as active avoidance. The specific structures which are essential for the acquisition of a classically conditioned fear response need further investigation.
\end{abstract}

Brady, Schreiner, Geller, and Kling (1954) reported acquisition deficits in amygdalectomized cats trained in the active avoidance conditioning situation. Horvath (1963) replicated these findings for acquisition and also reported retention deficits in cats after amygdalectomy. Robinson (1963), using a modified Miller (1948) acquired drive test, also reported a learning deficit resulting from amygdalectomy in rats. The integrity of the amygdala is, therefore, essential for the learning and retention of an avoidance response.

The purpose of the present experiment was to extend these findings to an alternate conditioning procedure, the classically conditioned fear response (McAllister \& McAllister, 1971; Goldstein, 1960). Rats were subjected to bilateral amygdalectomy, and their performance latencies on acquisition of the classically conditioned fear response were compared with the performance of normal animals.

\section{METHOD}

\section{Subjects}

The Ss were eight naive male albino rats obtained from the Holtzman Company, Madison, Wisconsin. They were 90 days old on arrival and 130-147 days old at the start of the experiment. Their weights ranged from $342-451 \mathrm{~g}$. They were maintained ad lib, on Purina Rat Chow throughout the course of the experiment. There were four animals in the normal control group and four animals in the amygdalectomized group.

\section{Apparatus \\ The apparatus was a black conditioning box divided by a guillotine type door and a hurdle into two compartments of equal size. The compound CS was a buzzer and light. The UCS was a 60-cycle ac current conducted to the grid through a $250,000 \mathrm{ohm}$ series resistor. UCS intensity was $250 \mathrm{~V}$, ac, or $.83 \mathrm{~mA}$. Further details of the apparatus have been described earlier (Goldstein, 1960).}

*Preparation of this report was supported, in part, by Grant No 26-631-32 and by summer faculty fellowships awarded by the Indiana University Office of $R$ esearch and Advanced Studies. Charles Borneman, Jr. made the drawings. The writer wishes to express his appreciation to his wife, Daidee, for her patience and helpful comments. Andy Elledge typed the manuscript.

\section{Procedure}

An experimental session lasted for $3 \mathrm{~h}$ and was divided into a "classical" conditioning and "instrumental" test session. There were four experimental phases:

Phase I. Exploration. S was placed into the grid compartment, with the guillotine door raised, for a period of $10 \mathrm{~min}$. During this time, CS and UCS were off, and S explored both compartments. At the end of the 10-min exploration period, the guillotine door was lowered and $\mathrm{S}$ adapted to the grid compartment for $1 \mathrm{~h} 3 \mathrm{~min}$.

Phase II. Classical Conditioning. Classical conditioning trials were begun immediately after exploration and adaptation. Each trial consisted of one successive presentation of CS and UCS while S was in the grid compartment, with the guillotine door closed. The interval between CS and UCS onset was $4 \mathrm{sec}$, UCS duration was $1 \mathrm{sec}$, and CS and UCS were terminated simultaneously. Successive CS-UCS presentations were separated by 10 -min intervals. Ss were given nine CS-UCS presentations.

Ss were removed from the grid compartment three minutes after the start of the last conditioning trial. They were removed to the home cage in the animal room, where they were permitted to rest for $5 \mathrm{~min}$ with food and water available.

Phase III. Exploration. A second 10-min exploration session in the conditioning box was given immediately afterwards. A final 10-min period in the home cage was given at the end of the second exploration session.

Phase IV. Instrumental test trials. "Instrumental" hurdle-jump conditioning sessions were started immediately after the last period in the home cage. The purpose of the hurdle-jump trials was to measure the strength of classical "fear" conditioning. Ss were required to learn to jump across a hurdle from the grid floor into the wooden floor compartment when CS was turned on and the door separating the two compartments was opened. CS was turned off as soon as the response had been made. Ss were never given the UCS during this session and had been over the hurdle only during the 10-min exploration session.

Each $\mathrm{S}$ received 20 hurdle-jump acquisition trials during a 45-min test period that began $28 \mathrm{~min}$ after the last classical conditioning trial. Hurdle-jump acquisition trials were separated by 2-min intervals. Maximum CS duration permitted on any hurdle-jump test trial was $30 \mathrm{sec}$. If $\mathrm{S}$ had not crossed the hurdle by that time, $E$ lowered the door and, $10 \mathrm{sec}$ later, removed $\mathrm{S}$ from the grid compartment. Latencies of $30 \mathrm{sec}$ were recorded for such trials.

Surgical and Histological Procedures. The lesions were produced electrolytically with the aid of a Baltimore rat stereotaxic instrument. The stereotaxic coordinates used were $2.5-\mathrm{mm}$ posterior to the Bregma, $4.5-\mathrm{mm}$ lateral to the midline, $8.0 \mathrm{~mm}$ below the dural tissue. Lesions were produced with a 
2-mA current of 15-sec duration. Ss were run 7 days after the operation. At the conclusion of the experiment, the animals were sacrificed and frozen coronal sections of the brain were made and were examined microscopically. The location of the lesion was verified by comparing the sections with plates from the Konig and Klippel (1963) atlas.

\section{RESULTS}

The hurdle-jump response latencies were transformed to reciprocals and summed over blocks of five trials. The mean of a block of five trials was the score used in the statistical analysis.

Comparison of the amygdalectomized and normal groups by means of the trend analysis of variance (Edwards, 1960) yielded an $F$ which was significant beyond the .01 level of confidence $[F(1,6)=65.70]$. This result indicated that amygdalectomized Ss performed more poorly than normal Ss on the hurdle-jump task. Comparison of the performance measures on Test Trials 1-5 with Test Trials 16-20, for the amygdalectomized groups, indicated that there was no significant difference between the two test trial blocks $[F(1,3)=2.50]$, suggesting that the amygdalectomized Ss did not learn the hurdle-jump response. The test for trend over the five test trial blocks was significant beyond the .01 level of confidence $[F(3,18)=7.50]$, indicating that the normal Ss learned the hurdle-jump test response.

An $\mathrm{F}$ test calculated for the comparison between the pre- and postspontaneous activity measures for the normal Ss yielded an $\mathrm{F}$ of 30.25 , which was significant beyond the .05 level of confidence $(\mathrm{df}=1 / 3)$. This finding indicates that the conditioning procedure reduced activity in the normal $S s$ and the grid compartment may have become aversive for the normal Ss but not for the amygdalectomized Ss. Comparisons of the pre- and postconditioning time spent in the grid compartment for the amygdalectomized animals yielded a nonsignificant $F$, suggesting that the grid compartment did not become aversive for the amygdalectomized Ss.

A $t$ test calcualted for the comparison of the preconditioning activity of the amygdalectomized and normal Ss indicated that amygdalectomy reduced the general level of activity, $t(6)=6.25$.

\section{DISCUSSION}

The results of the present experiment indicate that bilateral amygdalectomy interferes with acquisition of a classically conditioned fear response. This finding is consistent with the results obtained for other fear-motivated behavior such as active avoidance (Brady, Schreiner, Geller, \& Kling, 1954; Horvarth, 1963). The amygdaloid complex is, therefore, essential for the acquisition of fear-motivated behaviors. In addition, amygdalectomy reduced the general level of activity. The deficit

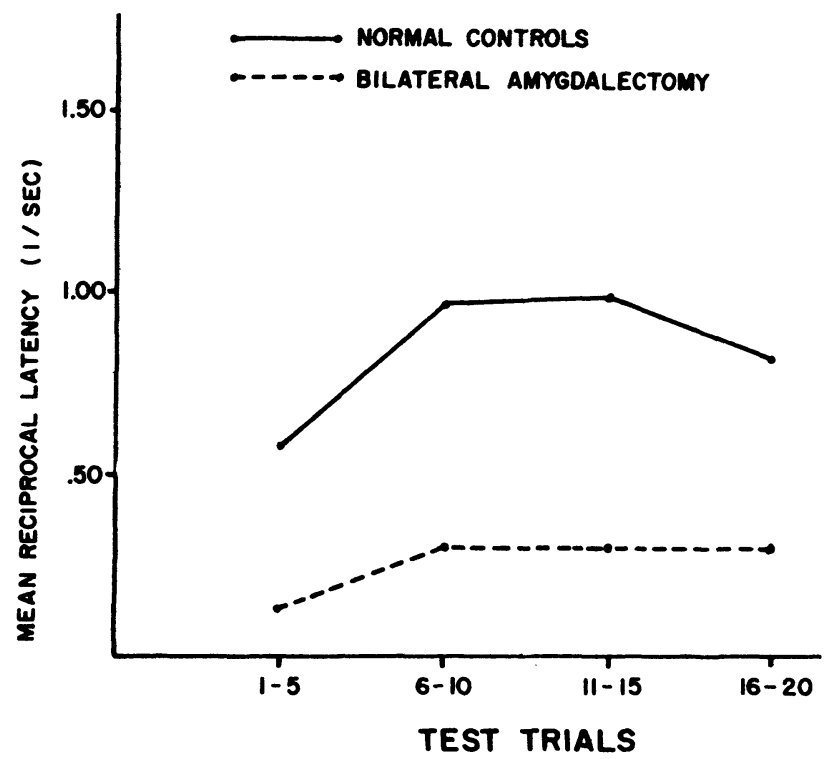

Fig. 1. Performance functions for the amygdalectomized and normal rats.

reported for the amygdalectomized animals is not an artifact resulting from operational shock, since sham operated rats $(\mathrm{N}=$ 2) yielded performance functions which were close to those of the normal rats.

The specific structures within the amygdaloid complex essential for the acquisition of a classically conditioned fear response need further investigation. The nature of the deficit, i.e., whether it is motivational or associational, cannot be determined from this experiment. The deficit may not be associational, however, since, during the classical conditioning session, the Ss reacted to the CS after a few CS-UCS pairings, by looking up at the light.

\section{REFERENCES}

Brady, J. V., Schreiner, L., Geller, I., \& Kling, A. Subcortical mechanisms in emotional behavior: The effect of rhinencephalic injury upon the acquisition and retention of a conditioned avoidance response in cats. Journal of Comparative \& Physiological Psychology, 1954. 47. 179-186

Edwards, A. L. Experimental design in psychological research. New York: Hold, Rinehart and Winston, 1960.

Goldstein, M. L. Acquired drive strength as a joint function of shock intensity and number of acquisition trials. Journal of Experimental Psychology, 1960, 60, 349-358.

Horvath, E. F. Effects of basolateral amygdalectomy on three types of avoidance behavior in cats. Journal of Comparative \& Physiological Psychology, 1963, 56, 388-389.

Konig, J. R. R., \& Klippel, R. A. The rat brain: A stereotaxic atlas. Baltimore: Williams \& Wilkins, 1963.

McAllister, W. R. \& McAllister, D. E. Behavioral measurement of conditioned fear. In Brush, F. R. (Ed.) Aversive conditioning and learning. New York: Academic. Press. 1971. Pp. 105-179.

Miller, N. E. Studies of fear as an acquirable drive: I. Fear as motivation and fear-reduction as reinforcement in the learning of new responses. Journal of Experimental Psychology, 1948, 38, 89-101.

Robinson, E. Effect of amygdalectomy on fear-motivated behavior in rats. Journal of Comparative \& Physiological Psychology, 1963, 56, 814-820.

(R eceived for publication August 21, 1974.) 